make-up, temperature and other factors may also have some importance. The solitary phase may be regarded as more juvenile than the gregarious one, and recent experiments have shown that the prothoracic gland which normally determines a juvenile morphology persists throughout life in the solitaria although disappearing early in the adult gregaria. Dr. Kennedy suggested that solitaria is adapted to a 'soft' habitat where food is available without much movement. Gregaria is suited to a 'hard' habitat which can be exploited only by the continuous movement which is typical of the phase. The polymorphism as a whole allows the species to $\theta x-$ ploit a much wider habitat than one phase could alone.

Dr. J. H. Sang, speaking on the environmental control of mutant expression, dealt with a developmental problem. In the course of growth a gene may produce a graded response in an enzyme which nevertheless has a discontinuous effect on adult development. Thus the gene 'antennaless' in Drosophila determines 0,1 and 2 antennæ but nearly always perfect structures. This is because the action of the gene occurs during a very short but welldefined period, namely, between the seventieth and eightieth hours of larval growth. This is shown by transferring larvæ of various ages to a different culture medium, for the effect of the gene can largely be nullified by suitable food. Such examples suggest how polymorphism might be determined by either a genetic or an environmental switch mechanism, in which influences at the right state of growth may produce large and discontinuous changes in the adult.

Prof. V. B. Wigglesworth, in a tentative synthesis, drew analogies between the polymorphism of cells in different parts of the body, the polymorphic aspect of insect metamorphosis and the phenomena which the other speakers had discussed. He showed that there seemed to be a complete transition from variation in which genetic determination was almost absolute to that in which external environmental factors decided between several alternatives.

The animated discussion which followed the invited contributions did not bring forward many really new points but was ehiefly concerned with the relative importance of genetic and non-genetic factors in particular examples. Terminology was also discussed, and some speakers were unwilling to speak of polymorphism unless the variations were clearly discontinuous. The suggestion, however, was made that the best distinction was between situations in which there is selection for increased variability as opposed to the more normal case where deviations are discouraged.

O. W. RICHARDS

\title{
MOLECULAR BIOLOGY AND POPULATION STRUCTURE
}

\begin{abstract}
A SYMPOSIUM on "Molecular Biology and Population Structure" was held at Norwich on the afternoon of September 4 at a joint session of Sections D (Zoology) and K (Botany) of the British Association for the Advancement of Science. The aim of the symposium was not so much to present new discoveries as to demonstrate to the audience the interrelations of recent discoveries in these fields, and to discuss some of their implications.

The symposium was opened by Dr. T. Alderson (British Empire Cancer Campaign), who described what we know of the structure of deoxyribonucleic acid (DNA) and brought out some of the evidence that genetic differences as we observe them are the resultant effects of differences of DNA molecules. Dr. J. A. Pateman (University of Cambridge) followed with a discussion of the evidence that gene differences have their effects by influencing the structure of protein molecules, though in discussing, at the end of his review, the recently discovered class of genes that appear to have the capacity of "turning on and off" whole metabolic sequences, he pointed out that there is evidence that these do not operate by producing proteins. These new regulator genes may well prove of major importance for our understanding of differentiation. Prof. H. Grüneberg (University College, London) then made the connexion between enzymes and more conventional characters by describing some beautiful examples, from his work with mice, which showed how the little invisible differences in chemical structure may be magnified during embryological development into the larger more obvious differences with which the study of genetics began.
\end{abstract}

At this point the symposium turned to what at first sight was another topic altogether, when Prof. J. M. Thoday (University of Cambridge) described how a variety of genes may be maintained in a population if that population were exposed to a variety of demands. Dr. P. M. Sheppard (University of Liverpool) then went on to discuss some of the evidence, illustrated from his work on butterflies, that the variety of genetic types in a population are not only directly adapted to the variety of conditions which the members of the population can exploit to promote survival, but must also be adapted to one another. The population is an integrated unit, and over the generations the genetic contents of different components of the population are judged not only by their individual success but also by the degree to which they co-operate with one another when brought together in sexual reproduction. The chromosomes of a population have not only to have genetic properties that are to be understood in terms of the needs of individuals but also other genetic properties only to be understood in terms of the population as a whole. Among other things the chromosomes of different individuals have to be coadapted to one another if the population is to function successfully over the generations.

Dr. C. A. Clarke (Royal Infirmary, Liverpool) followed. Dr. Sheppard with a little of the evidence that all these principles apply to man just as much as to Drosophila, or butterflies.

Prof. J. M. Thoday gave the final paper. $\mathrm{He}_{\mathrm{e}}$ pointed out that the two most striking discoveries of modern genetics had been brought together in this symposium.

The first discovery concerns the molecular nature of the genetic material. It has, of course, long been supposed that genes are molecules of some sort or another, but the precise knowledge of their molecular nature we are now acquiring is one of the most spectacular achievements of biology. 
The second discovery is of a different kind and was less expected. Both mathematical studies concerning the way genes might be supposed to behave in populations, and the biochemical concept that genetic variation means variation of the enzyme content of individuals, led us to expect that a population should be rather uniform genetically, each individual having much the same genetic make-up as other individuals. Further, this is the expectation we seem instinctively to tend towards in our attitude to our own populations, in our concept that the people we know and with whom we have a sense of belonging are essentially like ourselves.

It was this belief in the relative genetic uniformity of populations that gave such interest to the pioneer investigation of cases of obviously polymorphic populations which formed evident and striking exceptions to this expectation. Polymorphic populations are populations in which two alternative genes are both frequent, whereas simple theory would lead us to expect one to oust the other so that the population would tend to uniformity. One case of polymorphism, sickle-cell anæmia in man, mentioned in a number of the papers, provides an example where population genetics and molecular biology tio up closely together.

Study of such polymorphisms not only led to their explanation but also helped us to make the discovery that cases of polymorphism such as Dr. Sheppard discussed are far from being exceptional. They are only the striking and obvious examples of what is a normal phenomenon. For the expectation of genetic uniformity is not in the least borne out by fact in any well-studied population. The facts are quite contrary. Populations of sexually reproduced species consist of a wide variety of genetically different individuals and the genetic differences are in fact usually greater than the differences that we can see. So great is this genetic variety that we may go so far as to say that no two individuals (apart from identical twins) are genetically alike. This applies not only to flies and butterflies but also to man; in fact the evidence that it is true for man is probably more complete than it is for any other organism. Each of us is genetically different from all the others. This genetic or biochemical individuality is one of the major facts of life.

Along with the discovery of this genetic, or biochemical, individuality has come explanation of it at least in general terms. The basic explanations are two.

The first invokes the fact that we live, and all our ancestors have lived, in an environment that changes slowly with time. It ehanges as the climate changes, and it changes as other organisms change. We, that is the species to which we belong, have therefore inherited from the ancestral populations from which we have descended the means to change as the environment changes, a means that permits change in directions the necessity of which could not be foreseen. Sexual reproduction. which permits the generation of a variety of genetically different individuals, and death, which permits the elimination of those individuals less-well adapted or no longer adapted to the environment, provide that means of ehange. Sexual reproduction, however, only permits the generation of a variety of genetically new individuals, it does not ensure it unless there already is a variety of individuals. Hence, in the long term, natural selection in a changing environment must result in the continued survival only of populations that contain and always contained enough genetic variety to be able to produce the new variants that new environments require.

The second explanation is one which has developed more recently. It is not an alternative to but supplements the first. This explanation invokes the fact that the environment in which a population lives is not uniform in space. Different parts of the population meet different environments. Hence we must expect that, in different parts of a population, genetically different kinds will tend to be the fitter, so that variation of the environment in space must lead to the selection of genetical variety within the population. The results of the laboratory work done to tost this view lead to the conclusion that this is a most powerful factor; selection for variety is astonishingly successful.

We therefore begin to have an understanding of the function in life of this surprising biochemical variety that has been found in natural populations. It is the basis of the means of maintaining the population successfully in conditions that vary with space and change with time, and it is the prerequisite of innovation.

Prof. Thoday went on to discuss at some length some of the implications of this knowledge as it applied to man, pointing out that, though we know little of the genetics of normal variation in man and need much research on it, we do know enough to be sure that within the range of what are called. normal humans there is every sort of variety to be found. Each of us is different in molecular constituents that affect all classes of characteristics, whether physical or mental. How much vitamin we need to remain healthy, what our normal blood pressure is, what our taste preferences may be, how sociable we are, how quick in the uptake, how liable to fall to temptation; most things will be affected by our innate molecular constitution as well as by our upbringing.

This is not to deny the plastic adaptability of Homo sapiens. Plasticity of the individual is one of the striking properties of man, and environment in the general sense, which includes other people and upbringing in particular, can have great effects on the characteristics of human individuals. Nevertheless, we may be sure that the effect that a particular environment and upbringing will have on one man will differ from its effects on other men. Their genetic differences will ensure that this is so.

Now this is a consequence of our knowledge to which we shall find it difficult to adjust ourselves, but it has a bearing on almost every important human topic we discuss, because most important problems in some way or other involve the question of the justice of inequality in human society. Contemporarily, questions of equality in educational opportunity and the justice of giving the more promising in so far as we can assess them, better opportunities in grammar schools, provide an excellent example of a topic in which the facts of genetic variety are seldom dispassionately considered. But we must, some time, face the question of the relation between such topics and our knowledge that most, if not all, differences between people, and between classes of people, are in part genetic as well as being in the remaining part environmental in causation. Our sense of justice goes against accepting the fact that some people are biologically better endowed than others from the point of view of their capacity to profit from education and their capacity to return to society a profit on the cost of their education. But it is a fact nevertheless : 
life is not just in this sense. It is time that we realized that all men are of equal value just because all men are different. Some are better for some purposes, some for others and their variety, which is the basis of the richness of life, is at their initiation there, a cardinal fact of life, arising from the uniqueness of the molecules that form their basic genetic endowment. Society should be organized to profit from that individuality, not suppress it, however inconvenient it may be to bureaucrats and massproduction marketers. Further, if we could but accustom ourselves to the fact of human variety we might less often fall into the errors to which the type concept leads in our attitude to the differences between classes and between races. The hidden genetic variety within a group is much more striking than are the evident differences that distinguish groups within a species.
J. M. THODAY

\section{BIOLOGY IN BRITAIN}

$\mathrm{P}^{\mathrm{R}}$ ROGRESS within any major branch of science is inevitably uneven. Thus, there has been in the post-War period very rapid scientific advance in certain aspects of biological science particularly amenable to study by modern chemistry and physics. Unaware of the outstanding problems of biological science this has led some authors to advance such judgments as "modern science has all but wiped out the borderline between life and non-life" 1 . Such over-enthusiastic assessments in their extreme form amount, as Commoner ${ }^{2}$ has pointed out, almost to a declaration that biology as a separate science is no longer needed. Perhaps more dangerous is the reaction which now calls for a unifying of biological science by amalgamating existing disciplines in a way which, in practice, effects their contraction or elimination in fuvour of new, fashionable but frequently very restricted 'subjects'. Further, the call for such changes is often prefaced by the contention that established biology teachers are out of touch with modern biology. Dr. Wyatt's recent article ${ }^{3}$ is tinged with this approach.

His statement "the classical biology of pre-War years has changed little" is placed in a context which clearly implies its decreasing relevance to the main stream of biological thought rather than emphasizing that its slower development arises both from the resistance of many of its major problems to rapid solution and a lack of research resources. His contention that the American biology graduate is better equipped to teach other subjects (a rather doubtful role), to read the journals and to do and to direct research is too sweeping, despite the excellence and breadth of the biological education offered in some American universities. His contention that British students may learn more about modern biology from The New Scientist, the Penguin Science Survey and television than they gain from the isolated subject studied at a university at best displays lack of knowledge of many existing degree courses and of the separate and complementary role of important media of general scientific education.

Dr. Wyatt's solutions for the difficult problems facing many of us who are concerned with training biologists are too easy. For example, he finds the course for the diploma of technology in applied biology far, I imagine, beyond the hopes or intentions of its originators, to be more suited for academic biology and research than are the courses (and this presumably means any and all courses) offered at the universities.

It should be emphasized that there is ample evidence that, in Britain and other countries, teachers of biology are at present deeply involved in a re-assessment of their teaching programmes. For example, in March of this year, at a meeting attended by almost all the professors of botany in British universities, very careful consideration was given to such problems as: the sixth-form courses most appropriate for those intending to become biologists (emphasizing the need for basic training in the physical sciences and in mathematics); the rapidly changing character of university courses and the need for improved facilities, particularly for teaching in biochemistry, physiology and genetics; the influence of present Government statements on the recruitment to biology of first-class students and the financing of fundamental biological research. Further, new science buildings are being used to bring under one roof, and hence into close contact, groups of related departments, as exemplified by the new Biology Building at Birmingham and the Natural Sciences Building in my own University College. Biologists who, in their undergraduate courses and postgraduate work, have specialized in biochemistry, biophysics, microbiology and genetics are increasingly being appointed to existing departments of botany and zoology.

Dr. Wyatt rightly raises the question of the establishment of departments of biology as against continuing along a pathway of increasing fragmentation. This is in line with the recent memorandum of a Royal Society Committee consisting of fifteen of its Fellows, representative of all the major fields of biology. Insulated, introspective departments, if entrusted with the teaching of any branch of biology, will inevitably tend to deny to their students the value of the collaborative activity which has so evidently been effective in making many recent advances in our science. Nevertheless, there are dangers and difficulties in fully and quickly effecting the proposed re-organization. One of the difficulties hampering effective biology teaching is only now being eased by the present rapid expansion of higher education. Only recently in many institutions has it become possible to build up towards a teaching staff in biology whose training and research interests are sufficiently varied to give the desired range of related courses. One of the dangers is revealed in Dr. Wyatt's approach when, specifically mentioning as staff members, an ecologist, a physiologist, a biochemist, a microbial geneticist, a plant pathologist and perhaps an embryologist, he contends that courses in zoology, botany, biochemistry and microbiology, as well as in chemistry, can be made available by a biology department. The danger here, in its extreme form, is that 'molecular biology', instead of being visualized as a major and active field of discovery, is put forward as already synonymous with the whole of biology. This danger is, in fact, at present a matter of deep concern to many distinguished American biologists. The Royal Society Committee, taking a broader view 